\title{
Prognostication of successfulness in arm-wrestling on the base of morphological functional indicators' analysis
}

\author{
Podrigalo L.V. ${ }^{1}$, Galashko M. N. ${ }^{1}$, Iermakov S.S. ${ }^{2}$, Rovnaya O.A. ${ }^{1}$, Bulashev A.Y. ${ }^{1}$ \\ ${ }^{1}$ Kharkov State Academy of Physical Culture \\ ${ }^{2}$ Kharkov National Pedagogical University
}

\begin{abstract}
Purpose:

to work out methodic of arm wrestling successfulness prognostication by morphological functional indicators and substantiate it.

Material: $\quad 189$ sportsmen (of age $21.62 \pm 0.85$ years) were tested. We fulfilled goniometric testing of arms' joints ( $n=27)$ and hand dynamometry $(n=50)$. Characteristics of physiological tremor were studied $(n=29)$. Strength of forearm's muscles was determined $(n=33)$ as well as the strength of hand fingers' extensors separately $(n=50)$. Prognostication was realized with the help of sequential procedure by Wald's methodic, with calculation of prognostic coefficients and their informative potential.

Results: $\quad$ prognostic table, containing functional state indicators of arm-wrestlers. It contained 18 criteria. The criteria illustrate power, goniometric and functional indicators. Informative potential varied within $64.70-6.33$. The sense of prognosis is assessment of results and determination of appropriate prognostic coefficient. Besides, prognosis implies summing up of these coefficients for achievement of one of prognostic thresholds. The value of these thresholds was determined at level of \pm 13 , that corresponds to $95 \%(p<0.05)$ probability. Achievement of threshold +13 and more means sportsman's successfulness higher level. In case of lower threshold achievement successfulness probability is low.

Conclusions: the conducted researches permitted to work out methodic of arm wrestling successfulness prognostication by morphological functional indicators and substantiate it. The offered methodic is based on sequential analysis by Wald and is a simple, informative and objective tool of arm-wrestlers' condition control.

Keywords: arm-wrestling, morphological functional, indicators, prognosis.
\end{abstract}

\section{Introduction}

The problem of sportsmen's successfulness prognostication is one of central in sports. The study of sportsmanship levels, determination of correlations between them permit to optimize selection of promising sportsmen and prognosticate their competition functioning.

The basis of prognosis includes different indicators, characterizing sportsman’s condition. For example, Baláš J. et al. [23] found that arms' strength and endurance are the most informative indicators for prognostication of mountaineers' successfulness. Dummer G.M. et al. proved prognostic significance of arms' strength for successfulness in swimming [25]. Analogous studies were fulfilled in golf [39]. Klimczyk M. et al. studied correlations between efficiency and physical parameters of pole vaulting jumpers [33]. The authors proved possibility of prognosis with the help of determination of correlations between the studied indicators.

Aksutin V.V., Korobeynikov GV. offered to study special workability and psycho-physiological state for prognostication elite boxers' successfulness [21]. Brezhniev A.M. et al. offered to predict volleyball players' game fitness on the base of information about their competition functioning. It permitted to receive information about weak and strong sides of training and correct the training process [2]. This approach is based on assessment of volleyball players' technical efficiency in games. The authors proved purposefulness of Kohonen

\footnotetext{
(C) Podrigalo L.V., Galashko M. N., lermakov S.S.,

Rovnaya O.A., Bulashev A.Y., 2017
}

doi:10.15561/20755279.2017.0108 nets' application, which shall be adjusted by results of two previous games and predicted estimation of next game.

Latyshev S.V. regarded prognostication in free style wrestling [8]. The author notes that prognostication of wrestler's successfulness is possible only by comparing his results with appropriate model characteristics at every training stage [8]. Formation of model pictures shall be realized in several directions. It implies modeling of wrestler's fitness in certain age stage of selection. With it, informative parameters are: health state, fitness indicators, sport result and its dynamic.

Kudriashova T.I. et al. used analysis of correlations between load indicators in shot put. The authors constructed linear regression model of efficiency prognostication [7]. The data of other research permitted to predict results in 600 meters' run on the base of the following indicators: physical condition and physical fitness of girls; parameters of cardio-vascular and central nervous system's functional potentials [15]. Pomazan A.A. used results of anthropometric data correlation analysis and indicators of 4-6 years' age children's physical abilities [13]. The author found the most informative indicators for determination of promising for sports children [13].

Yavorskaya T.Ye. predicted efficiency in sports by a number of statistic methodic (regression, vector, matrix, dispersion and factorial analysis, theory of multidimensional linear regression in Euclid space) [19]. By the data of other work efficiency prognostication in long and super long distances run shall be fulfilled, basing on aerobic and anaerobic metabolism indicators [6].

In other research mathematical models for 
prognostication of 9-16 years' Judo wrestlers' successfulness with accuracy up to $81 \%$ were offered [17]. As foundation the authors took anthropometric and psycho-physiological parameters. Shyan V.N. and Shamardin V.N. worked out prognostication technology for badminton players' achievements [18]. For the worked out analytical models of sportsmen the authors used functional, pedagogic and psycho-physiological criteria. They offered integral criterion, for prospects' assessment by 9-points' scale. Zaporozhanov V. et al. proved possibility of metrical calculation method for determination control testing results' reliability, which are used for diagnostic of psycho-physical suitability and sportsmanship's prognostication [5]. The authors calculated metrical assessments of measurements' reliability (stability, concordance and informative potential of control data) for current diagnostic of sport potentials of the tested.

Bobrovnik V.I. worked out system for assessment and prognostication of qualified light athletes' physical condition. Such approach stipulates complex of pedagogic tests, estimation tables, assessment of functional state (of vegetative, nervous and cardio vascular systems as well as external respiratory system [1]. The received results permitted to find criteria of main organism systems' physical fitness functional state, which influence on high sport results achievement.

Gaskov A.V. et al. determined importance of general and special physical fitness indicators for successfulness in boxing [26]. The built by them models differed, depending on sportsmen's training stage. In other researches ways for training optimization on the base of models for sport future prediction are described [24, 28, 29]. In such cases registration of sportsmen's morphological functional indicators is very important [35]. Popov Th. I. et al. developed prognosis of successfulness before cadets' summer training period. The basis of this prognosis was the results of psychological-professional selection, physical and simulators' training complex analysis [14]. Importance of complex assessment was stressed: as far as any of criteria does not give confident prognosis separately. Golets V.A. et al. substantiated possibilities of many-factorial express-diagnostic application for predicting reaction to physical load [4]. The found correlations between parameters permit to determine the persons of "risk group" and prevent from undesirable after effects of physical training.

Thus, the available data witness about possibility to prognosticate successfulness in sports on the base of morphological functional data. Such data are informative, accessible, and financially profitable. Mathematical methods, used in statistic, are the tools of prognostication. However, in arm wrestling this problem has not been solved finally. The existing situation conditions demand in working out complex prognostication methodic for arm wrestling successfulness, based on registration of morphological functional indicators.

The purpose of the present work is to work out methodic of arm wrestling successfulness prognostication by morphological functional indicators and substantiate it.

\section{Material and methods}

Participants: as main material 189 sportsmen (of age $21.62 \pm 0.85$ years) were tested. We fulfilled goniometric testing of arms' joints $(n=27)$ and hand dynamometry $(n=50)$. Characteristics of physiological tremor were studied $(n=29)$. Strength of forearm's muscles was determined $(n=33)$ as well as the strength of hand fingers' extensors separately $(\mathrm{n}=50)$.

Organization of the research: the scheme of the research stipulated division of participants into two groups: experimental group (sportsmen from $1^{\text {st }}$ category to master of sports) and control group (sportsmen of mass categories and students, training for recreation) [9-12, 36]. Prognostication was realized with the help of sequential procedure by Wald's methodic, with calculation of prognostic coefficients and their informative potential [22]. Mean values of morphological functional indicators were taken as bordering values. Then, probability of less or higher indicators' values in respect to mean values was determined. After that prognostic coefficients and information potential of the studied attributes were calculated.

In compliance with requirements of the methodic attributes shall be located in table in order of their information potential decreasing. Informational potential less than 5.0 was considered insignificant. Indicators with such or less value were not entered in the table. In case of equal informational potential the order of their location was determined randomly.

Statistical analysis: analysis of the received data was fulfilled with the help of licensed electronic tables Excel and calculation indicators of descriptive statistic [22]. Prognostic coefficients were calculated be the following formula:

$$
P C=10 \times \lg \frac{p\left(D_{1} / S\right)}{p\left(D_{2} / S\right)}
$$

Where PC is prognostic coefficient, $\mathrm{p}\left(\mathrm{D}_{1} / \mathrm{S}\right)$ probability of attribute presence, $\mathrm{p}\left(\mathrm{D}_{2} / \mathrm{S}\right)$ - probability of attribute absence.

Coefficient 10 is introduced for PC to have the form of a whole number to make prognostic procedure easier.

Informational potential was calculated by the formula of Kulbak:

$$
I=P C-1 / 2 \times\left[p\left(D_{1} / S\right)-p\left(D_{2} / S\right)\right]
$$

Where I -is informational potential of attribute. Other legend is the same as in the previous formula.

\section{Results}

The worked out prognostic table contains indicators, reflecting sportsmen's functional state. Considering probabilities of distinctions and informational potential 
of the registered indicators the table contains 18 criteria. These criteria illustrate power, goniometric and functional indicators (see table 1). Coefficients are dimensionless values and it permits to compare them and use for sportsmen's condition prognostication.

The highest quantity of the used attributes (12) is goniometric ones and reflects amplitude of arm joints' movements. Still 5 criteria illustrate relative strength of forearm's and fingers' muscles. 1 attribute characterizes tremor. Introduction of relative strength indices in prognostication procedure was conditioned by sportsmen's different weight categories. Power indicators directly depend on body mass. That is why application of absolute indicators for prognostication would be incorrect. Informational potential of the indicators varied within the range from 64.70 to 6.33 . For five goniometric indicators it was equal (10.46).

The table permits to prognosticate sportsmen's successfulness on the base of methodic and tests. The prognosis itself implies: assessment of results; determination of appropriate prognostic coefficient; summing up of these coefficients. Such approach permits to reach one of prognostication thresholds. In compliance with commonly accepted approaches thresholds' value was taken at level \pm 13 . It corresponds to probability of $95 \%(p<0.05)$. Reaching +13 (or more) threshold means high successfulness of sportsman. In case of reaching analogous negative threshold successfulness probability would be low and sportsman is not promising. If prognostication procedure resulted in reaching no thresholds, prognosis is considered to be indefinite. In such case additional tests are required for receiving additional information.

The offered methodic is of universal character and can be used at different stages of assessment of sportsman's functional state. All criteria are well controlled and can change in the process of optimally built training. Thus, the offered methodic can be used for successfulness prognostication at stage of preparation for competitions, for current control and assessment of training loads' adequacy.

\section{Discussion}

In context of present work solution of prognostication task implies choice of one from two available variants: if sportsman's fitness level is high or insufficient for success. The procedure of prognostication task's solution shall consider sportsmen's functional state and graduate the used methodic depending on their informational significance. Advantages of the used methodic (as per Wald) include: possibility of application with different character of attributes' distribution in the tested groups; absence of demand in indicators' calculation (error of mean value and mean square deviation); easiness and feasibility.

Selection of adequate and informative indicators is an important pre-condition of prognostication. Parola F., Musso E. note certain problems' existence in assessment of sportsmen's competition functioning [34]. They are: finding effective criteria for physical fitness assessment owing to specific aspects of arm wrestling.

Voronkov A.V. et al. say that the most important physical qualities in arm wrestling are: speed-power abilities; maximal power; power endurance. Importance of strength and speed for victory in arm wrestling is underlined also in other work [38]. The received by us results prove it: power indicators are characterized by high informational potential.

Table 1. Prognostication of arm wrestlers' successfulness

\begin{tabular}{|c|c|c|c|}
\hline \multirow[t]{2}{*}{ Indicators } & \multicolumn{2}{|c|}{ Prognostic coefficients } & \multirow{2}{*}{$\begin{array}{l}\text { Information } \\
\text { potential }\end{array}$} \\
\hline & Presence & Absence & \\
\hline Relative strength of right hand's moving aside more than $18.75 \%$ & 4 & -3 & 64.70 \\
\hline Bending of right shoulder joint more than $159^{\circ}$ & 2 & -3 & 43.79 \\
\hline Relative strength of right arm's pronation more than $36 \%$ & 2 & -1 & 43.21 \\
\hline Unbending of left elbow joint more than $21^{\circ}$ & 1 & -3 & 42.86 \\
\hline Relative strength of right hand middle finger more than $36 \%$ & 2 & -2 & 32.58 \\
\hline Bending of left wrist joint more than $66^{\circ}$ & 2 & -2 & 29.66 \\
\hline Moving of left shoulder joint more than $25^{\circ}$ & 1 & -2 & 18.99 \\
\hline Bending of right wrist joint more than $69^{\circ}$ & 1 & -2 & 18.37 \\
\hline Bending of left shoulder joint more than $160^{\circ}$ & 3 & -2 & 14.13 \\
\hline Relative strength of left hand moving aside more than $17,5 \%$ & 1 & -1 & 12.78 \\
\hline Time of right arm's tremor less than 23 seconds & 1 & -1 & 11.16 \\
\hline Right wrist joint's moving aside more than $42^{\circ}$ & 1 & -1 & 10.46 \\
\hline Right elbow joint bending more than $127^{\circ}$ & 1 & -1 & 10.46 \\
\hline Right elbow joints unbending more than $21^{\circ}$ & 1 & -1 & 10.46 \\
\hline Right shoulder joint moving aside more than $149^{\circ}$ & 1 & -1 & 10.46 \\
\hline Left shoulder joint moving aside more than $148^{\circ}$ & 1 & -1 & 10.46 \\
\hline Left elbow joint bending more than $129^{\circ}$ & 2 & -2 & 9.72 \\
\hline Relative strength of left hand middle finger more than $36.25 \%$ & 2 & -2 & 6.33 \\
\hline
\end{tabular}


The provided data witness about importance of movements' amplitude in arms' joints for prognostication in arm wrestling: most of attributes in tables are goniometric. The correctness of this assumption is proved in other research [27]. Analysis of typical for arm wrestling fracture of shoulder bone showed that this trauma is a result of external forces' impact: bending torque, axial pressing and twisting. Thus, just these movements shall be regarded as the main in this kind of sports and be studied for prognostication.

As it has already been noted successfulness in arm wrestling depends on complex of criteria and indicators. Such approach was realized when creating selection methods for arm wrestling [16]. The methodic implies determination of special power endurance, hand's strength, arms' strength and quickness of reaction. It is very close to criteria used by us. However, with similarity of criteria there is a difference in the applied methods. The first quality is assessed by maximal quantity of hands with bar bell bending (the weight of barbell is half of the weight of the tested). Hand's strength is assessed traditionally with hand dynamometry, while arm's' strength - by time of hanging on bent arms. Quickness of reaction is registered in tapping test. Result is received as total sum of points in compliance with specially worked out scales. On the base of these scales sportsman's suitability for arm wrestling is assessed. In our opinion substantial disadvantage of this methodic is absence of consideration of parameters' informational potential.

Optimality of exactly Wald's methodic for prognostication can be proved by presence of analogous works. In the process of substantiation and creation of model for arm wrestlers' functional state monitoring we worked out prognostication scale for prospects assessment in this kind of sports [37]. It included physical condition indices (relation of hand dynamometry to body mass; relation of forearm and shoulder arm lengths), biochemical indicators (relation of diene conjugates to the restored glutathione), bio-physical indicators (specific weight of electrically negative cells of buccal epithelium) and physiological indicators (results o "relay race test”). Application of indices permits to pass to relative indicators, i.e. to standardize prognostication procedure. Determination of the mentioned tests permits to assess sportsmen's prospects in arm wrestling. However, this methodic requires special equipment, chemical agents and tools. It substantially weakens its feasibility and increases the cost of assessment. If to exclude bio-chemical [3032] and bio-physical tests it will negatively reflect on its informative potential.

Akpinar S. C et al. worked out successfulness prognostication on example of participants of Turkey arm wrestling national championship [20]. The authors used morphological and functional indicators for prognostication. As successfulness predictors they noted arms' strength, time of hearing reaction, length and circumference of forearm. Such approach and received results also coincide with our data. But these authors did not consider joints' functional state, strength of separate fingers and forearm muscles. The authors did not use hand's fine coordination. It substantially weakens prognostication effectiveness.

Thus, analysis of literature data permits to conclude that choice of morphological functional indicators and tools for prognostication was correct.

\section{Conclusions}

The fulfilled researches permitted to work out scheme of sportsmen's successfulness prognostication with the help of morphological functional indicators and substantiate it. The offered methodic is based on sequential analysis by Wald and is a simple, informative and objective tool for control over sportsmen's condition. For determination of indicators to be used simple and accessible equipment is sufficient (pronometer, dynamometer, weights) that permits to speak about feasibility and financial viability of such prognostication method.

\section{Conflict of interests}

The authors declare that there is no conflict of interests.

\section{References}

1. Bobrovnyk VI. System of estimations and prognostications of bodily condition of skilled sportsmen in track-and-field. Pedagogics, psychology, medical-biological problems of physical training and sports, 2013;1:12-19. doi:10.6084/ m9.figshare.106930

2. Bregnev AM, Zezyulin VT, Bregnev TA, Zezyulin SV. Definition method of technically equal players in a command of professional volleyball. Pedagogics, psychology, medicalbiological problems of physical training and sports, 2009;4:20 - 23.

3. Voronkov AV, Nikulin IN, Filatov MS. Osobennosti razvitiia sily myshc-sgibatelej kisti i pal'cev v armsporte [Special aspects of training of hand and fingers' extensors in arm wrestling]. Kul'tura fizicheskaia i zdorov'e, 2010;4:18-20. (in Russian)

4. Holets VA, Evdokimov EI. The employment of S.A. Dushanins multifactorial express diagnostics for predicting response to physical stress. Physical education of students,
2009;3:6-11.

5. Zaporozhanov VA, Boraczynski Tomasz. Empiric reliability of diagnostic and prognostic estimations of physical standards of children, going in for sports. Pedagogics, psychology, medical-biological problems of physical training and sports, 2012;11:38-42. doi:10.6084/m9.figshare. 97355

6. Klochko LI. Forecasting to velocities harness racing on average, long, superlong distances (marathon run). Pedagogics, psychology, medical-biological problems of physical training and sports, 2010;5:73 - 75.

7. Kudrashova TI, Kolomoiets VN. The use of computers technologies is for prognostication of sporting results in the shotput. Pedagogics, psychology, medical-biological problems of physical training and sports, 2009;8:88 - 92.

8. Latyshev SV. The problem of selection and prognostication of sporting results in a freestyle wrestling. Pedagogics, psychology, medical-biological problems of physical training and sports, 2009;10:110 - 113. 
9. Podrigalo LV, Galashko MN, Galashko NI. Goniometric researches of armwrestling sportsmen. Physical Education of Students, 2013;1:45-48. doi:10.6084/m9.figshare.156357

10.Podrigalo LV, Galashko MN, Galashko NI. Study and evaluation of indicators of relationships motor analyzer sportsmen of armsport. Physical education of students, 2013; 17(3): 46-49. doi:10.6084/m9.figshare.669671

11.Podrigalo LV, Galashko NI, Galashko MN. Izuchenie sily pal'cev sportsmenov armsporta raznogo urovnia masterstva [Study of fingers' strength of different qualification arm wrestlers]. Sovremennoe sostoianie i tendencii razvitiia fizicheskoj kul tury i sporta, 2014;1:305-309. (in Russian)

12.Podrigalo LV, Galashko MN, Galashko NI, Prusik Krzysztof, Cieślicka Mirosława. Research of hands' strength and endurance indications of arm sport athletes having different levels of skills. Physical education of students, 2014; 18(2): 37-40. doi:10.6084/m9.figshare. 907140

13.Pomazan AA. Intercommunication of anthropometric indexes and physical capabilities of children 4-6 years in prognostication of sporting results in a gymnastics. Pedagogics, psychology, medical-biological problems of physical training and sports, 2010;2:113-117.

14.Popov FI, Marakushin AI, Gorelov AA. Influence of results phsycological - professional selection, physical and training preparations on success flying training of cadets. Physical education of students, 2010;3:72-74.

15.Samokih II. Prognostication of 600 meters race results of girls of 7-10 years. Pedagogics, psychology, medical-biological problems of physical training and sports, 2010;2:134 - 136.

16.Kochina ML, Galashko OI, Galashko OI, Galashko MI. Sposib doboru sportsmeniv dlia zaniat' armsportom [Sportsmen's selection for arm wrstling]. Ukraine patent 53307 UA. 2002 Jan 15.

17.Horiakov VA. Methodology for predicting the young wrestlers success of sporting activities in various stages of ontogeny. Pedagogics, psychology, medical-biological problems of physical training and sports, 2011;4:157 - 160.

18.Shyyan VN, Shamardin VN. Psychological characteristics of group cohesion athletes. Pedagogics, psychology, medical-biological problems of physical training and sports, 201;8:106 - 108.

19.Yavorskaya T. The peculiarities of prognosticating the athletic effectiveness as a factor of stepping up the potency of a training process. Pedagogics, psychology, medicalbiological problems of physical training and sports, 2010. № 3. C. 148 - 150.

20.Akpinar S, Zilel R, Senyuzlu E, Tunca SA. Anthropological and perceptual predictors affecting the ranking in arm wrestling competition. Int. J. Morphol., 2013;31(3):832-838.

21.Aksutin VV, Korobeynikov GV. Psychophysiological states and special performance of boxers with different styles of fight. Pedagogics, psychology, medical-biological problems of physical training and sports, 2014;12:3-6. doi:10.15561/18189172.2014.1201

22.Antomonov MIu. Processing and analysis of biomedical data, Kiev; 2006.

23.Baláš J, Pecha O, Martin AJ, Cochrane D. Hand-arm strength and endurance as predictors of climbing performance. European Journal of Sport Science. 2012;12(1):16-25. doi:1 0.1080/17461391.2010.546431

24.Bliznevsky AA, Kudryavtsev MD, Iermakov SS, Jagiello W. Formation of active-effective attitude of 12-13 years' judo athletes to sports functioning in competition period. Archives of Budo. 2016;12:101-15.

25.Dummer GM, Clarke DH, Vaccaro P, Vander Velden L,
Goldfarb AH, Sockler JM. Age-Related Differences in Muscular Strength and Muscular Endurance among Female Masters Swimmers. Research Quarterly for Exercise and Sport. 1985;56(2):97-102. doi:10.1080/02701367.1985.106 08442

26.Gaskov AV, Kuzmin VA, Kudryavtsev DM, Iermakov SS. Successfulness of general and special physical qualities' development on different stage of students-boxers' training. Physical Education of Students. 2016;20(1):4-11. doi:10.15561/20755279.2016.0101

27.Hyun-Soo Kim, Young Ho Shin, Youn Wha Kim. Comminuted fracture with butterfly fragment of the humerus sustained during arm wrestling. Biomedical Research 2013; 24 (3): 320-323.

28.Iermakov SS, Arziutov GN, Jagiello W. Quick training of students to judo techniques. Archives of Budo. 2016;12:1524.

29.Iermakov SS, Podrigalo LV, Jagiello W. Hand-grip strength as an indicator for predicting the success in martial arts athletes. Archives of Budo. 2016;12:179-86.

30.Jastrzebski Z, Zychowska M, Jastrzebska M, Prusik K, Kortas J, Ratkowski W, et al. Changes in blood morphology and chosen biochemical parameters in ultra-marathon runners during a $100-\mathrm{km}$ run in relation to the age and speed of runners. International Journal of Occupational Medicine and Environmental Health. 2016;29(5):801-814.

31.Kortas J, Prusik K, Flis D, Ziemann E, Leaver N, Antosiewicz J. Effect of Nordic Walking training on iron metabolism in elderly women. Clinical Interventions in Aging. 2015;10:1889-1896.

32.Kortas J, Prusik K, Flis D, Ziemann E, Leaver N, Antosiewicz J. Possible effect of decreased insulin resistance on ferritin levels after Nordic Walking training Reply. Clinical Interventions in Aging. 2016;11:150-155.

33.Mariusz Klimczyk, Agata Klimczyk. Prognosis of training effects based on somatic characteristics and sport result. Pedagogics, psychology, medical-biological problems of physical training and sports, 2015;6:48-55. doi:10.15561/18189172.2015.0608

34.Parola F, Musso E. Market structures and competitive strategies: the carrier-stevedore arm-wrestling in northern European ports. Maritime Policy \& Management. 2007;34(3):259-278. doi:10.1080/03088830701343369

35.Podrigalo LV, Iermakov SS, Alekseev AF, Rovnaya OA. Studying of interconnections of morphological functional indicators of students, who practice martial arts. Physical Education of Students. 2016;20(1):64-70.

36.Podrigalo LV, Iermakov SS, Nosko MO, Galashko MN, Galashko NI. Study and analysis of armwrestlers' forearm muscles' strength. Journal of Physical Education and Sport, 2015;15(3): 531 - 537. doi:10.7752/jpes.2015.03080

37.Podrigalo LV, Istomin AG, Galashko NI. Monitoring funkcional'nogo sostoianiia sportsmenov $v$ armsporte [Monitoring of the functional state of the athletes in arm sport], Kharkov, KNMU Publ., 2010. (in Russian)

38.Song Q, Yu Y, Ge Y, Gao Z, Shen H, Deng X. A realtime EMGdriven arm wrestling robot considering motion characteristics of human upper limbs. Int. J. Human Robot., 2007;4(4):645-670.

39.Sung DJ, Park SJ, Kim S, Kwon MS, Lim Y-T. Effects of core and non-dominant arm strength training on drive distance in elite golfers. Journal of Sport and Health Science. 2016;5(2):219-225. doi:10.1016/j.jshs.2014.12.006 


\section{Information about the authors:}

Podrigalo L.V.; http://orcid.org/0000-0002-7893-524X; I.podrigalo@mail.ru; Kharkov State Academy of Physical Culture; Klochkovskaya str. 99, Kharkov, 61022, Ukraine.

Galashko M. N.; http://orcid.org/0000-0001-5278-9806; infiz@kharkov.ukrtel.net; Kharkov State Academy of Physical Culture; Klochkovskaya str. 99, Kharkov, 61022, Ukraine.

Iermakov S.S.; http://orcid.org/0000-0002-5039-4517; sportart@gmail.com; Kharkiv National Pedagogical University; Artema str. 29, Kharkov, 61002, Ukraine.

Rovnaya O.A.; http://orcid.org/0000-0003-1519-5632; rovnayaolga@mail.ru; Kharkov State Academy of Physical Culture; Klochkovskaya str. 99, Kharkov, 61022, Ukraine.

Bulashev A.Y.; http://orcid.org/0000-0002-3542-5688; I.kaplina7@mail.ru; Kharkov State Academy of Physical Culture; Klochkovskaya str. 99, Kharkov, 61022, Ukraine.

Cite this article as: Podrigalo LV, Galashko MN, Iermakov SS, Rovnaya OA, Bulashev AY. Prognostication of successfulness in arm-wrestling on the base of morphological functional indicators' analysis. Physical education of students, 2017;1:46-51. doi:10.15561/20755279.2017.0108

The electronic version of this article is the complete one and can be found online at: http://www.sportedu.org.ua/index.php/PES/issue/archive

This is an Open Access article distributed under the terms of the Creative Commons Attribution License, which permits unrestricted use, distribution, and reproduction in any medium, provided the original work is properly cited (http://creativecommons.org/licenses/by/4.0/deed.en).

Received: 26.12.2016

Accepted: 15.01.2017; Published: 10.02.2017 